\title{
Physical exercise and body-mass index in young adults: a national survey of Norwegian university students
}

\author{
Michael Grasdalsmoen ${ }^{1}$, Hege Randi Eriksen ${ }^{1}$, Kari Jussie Lønning ${ }^{2,3}$ and Børge Sivertsen ${ }^{4,5,6^{*}}$ (D)
}

\begin{abstract}
Background: Physical inactivity and obesity pose a major public health challenge. The aim of this study was to describe the level of physical exercise and body-mass index in college and university students, as well as to examine potential changes from 2010 to 2018.

Methods: Data stem from the SHoT study, a national student health survey for higher education in Norway, conducted at 4-year intervals. The SHOT studies conducted so far in 2010, 2014 and 2018, included 6053, 13,525 and 50,054 fulltime students (aged 18-35), respectively. Exercise frequency (average number of times exercising each week) was assessed in all three waves, and was used for the trend analysis. The last wave in 2018 also assessed the average intensity and duration of the exercise.

Results: Overall, students exercised less in 2018 compared to 2014, but comparable to level in 2010. The prevalence of overweight increased substantially from 2010 to 2018, but especially in the last 4 years and among older female students. Less than one of four male, and one of five female students, met the recommended criteria for both exercise frequency, intensity and duration. As expected, the associations between exercise and overweight/obesity were in a dose-response manner, and strong across all three waves.

Conclusions: Our findings show that the large majority of young adults fail to meet international recommendations on exercise, and that the proportion of overweight is increasing in both genders and across all age groups. We conclude that there is an urgent need for a broad approach to achieve a paradigm shift in supporting our college and university students to become more active.
\end{abstract}

Keywords: College students, Physical exercise, Body-mass index, Epidemiology, Trend

\section{Introduction}

Research on overweight and obesity shows that the prevalence has increased substantially across the globe over the last decades. One third of the world's population can now be categorized as being overweight, and all signs point to a further escalation in the years to come [1]. What may be labelled as the global obesity epidemic is an obvious public health concern, given the many and extensive negative health consequences.

\footnotetext{
* Correspondence: borge.sivertsen@fhi.no

${ }^{4}$ Department of Health Promotion, Norwegian Institute of Public Health,

Postboks 973 Sentrum, 5808 Bergen, Norway

${ }^{5}$ Department of Research and Innovation, Helse Fonna HF, Haugesund,

Norway

Full list of author information is available at the end of the article
}

The obesity epidemic can largely be explained by either failure to restrict energy intake, and/or too low levels of energy expenditure. While the relative importance of these factors is still debated $[2,3]$, there is general agreement that a sedentary lifestyle is one of the most prominent risk factors for the increase in body-mass index (BMI). Despite public health efforts aimed at encouraging individuals to eat healthier and to exercise more, no country has yet been successful in reversing the obesity rates observed during the past 30 years. Public health efforts regarding exercise have included establishing guidelines on the level of physical activity, and provided recommendations and guidance on both the frequency, duration, and intensity of physical activity. For example, the US Centers for Disease Control and Prevention recommend that adults (aged 18-64 years) should get at 
least $30 \mathrm{~min}$ (or preferable $60 \mathrm{~min}$ for increased health benefits) of moderate to vigorous physical activity (MVPA) at least 5 days per week [4]. The World Health Organization (WHO) have published very similar recommendation, and have aimed to reduce the prevalence of insufficient physical activity by $10 \%$ by 2025 [5]. However, recent evidence show that such efforts have largely been unsuccessful, with a report from the Global Burden of Disease (GBD) study showing that the world's level of inactivity has not improved from 2001 to 2016 [6]. While our leisure-time activity level has progressively increased over the years [7]; this has not been enough to counterweigh our increased sedentary lifestyle, as our total physical activity level seems to be declining globally [8].

College and university students may be especially at risk for sedentary behaviour, as much of their campus day consists of classroom lectures and studying sitting still. On the other, young adults are typically in good health, and both educational institutions and student welfare associations facilitate their students to engage in various forms of physical activity. Indeed, studies have suggested that university students are both highly sedentary and highly active $[9,10]$. However, most studies in this field have been conducted on young undergraduate students, often focusing on the transition between late adolescence and young adulthood. Less is known to what extent the association between physical activity and BMI changes with increasing age within the student population. And importantly, there is a paucity of studies investigating if level of physical activity among university students have changed over the decade, and to what extent this may related to the increasing prevalence on overweight and obesity. Expanding our knowledge on these issues in college populations may be especially important, as sedentary behaviour in this age may represents a continued snowballing risk for the development of poor health.

Based on these considerations, the aim of this large national study from 2018 was fourfold: 1) to investigate the current level of physical exercise among male and female college and university students in terms of how many meet the international recommendations of frequency, intensity and duration of exercise; 2) to explore the trend of both physical exercise and BMI from 2010 to 2018 ; 3) to examine the association between physical activity and overweight across different age cohorts within the student population and 4) to examine the strength of the association between exercise frequency and BMI from 2010 to 2018.

\section{Methods}

\section{Procedure}

The SHoT study (Students' Health and Wellbeing Study) is a large Norwegian student survey for higher education, conducted by three largest student welfare associations. Since 2010, three waves have been completed. Detailed information of the SHoT study has been described in a previous publication [11], but in brief, data from the SHoT2018 was collected from February to April, 2018, and included all fulltime Norwegian students aged 18-35, taking higher education. In this wave, 162,512 students received an invitation to participate, of whom 50,054 students completed the web-based questionnaires (response rate: $30.8 \%$ ). The SHoT2014 study took place from February to March, 2014. In all, 47,514 randomly invited students aged 18 to 35 (stratified by institutions, faculties, and departments) received the online questionnaires, of whom 13,525 students participated (response rate: $28.5 \%$ ). The first SHoT study, conducted from October to November 2010, were smaller and included 6053 participants of the originally invited 26, 779 Norwegian students, also aged between 18 and 35 (response rate of 22.6\%).

\section{Instruments \\ Demographic information}

All students provided data on their age and gender. In the current study, the participants' age was categorized into five groups $(18-20$ years [18\%, $n=8832], 21-22$ years $[31 \%, n=15,471], 23-25$ years $[32 \%, n=15,902], 26-28$ years [12\%, $n=5710]$, and $29-35$ years [ $7 \%, n=3427]$ ).

\section{Physical activity}

The students were first presented with the following brief definition of exercise: "With exercise we mean that you for example go for a walk, go skiing, swim or take part in a sport". Physical activity was then assessed using three sets of questions, assessing the average number of times exercising each week, and the average intensity and average hours each time [12]: 1) "How frequently do you exercise?" (Never, Less than once a week, Once a week, 2-3 times per week, Almost every day); 2) "If you do such exercise as frequently as once or more times a week: How hard do you push yourself? (I take it easy without breaking into a sweat or losing my breath, I push myself so hard that I lose my breath and break into a sweat, I push myself to near-exhaustion); and 3) "How long does each session last?" (Less than $15 \mathrm{~min}, 15-29$ min, $30 \mathrm{~min}$ to $1 \mathrm{~h}$, More than $1 \mathrm{~h}$ ". This 3 -item questionnaire has previously been used in the large population-based Nord-Trøndelag Health Study (the HUNT studies). Previous validation studies $[12,13]$ have demonstrated moderate correlations between the questionnaire responses and direct measurement of $\mathrm{VO}_{2} \max$ during maximal work on a treadmill ( $r=0.43$ [frequency], $r=0.40$ [intensity] and $r=0.31$ [duration]), with ActiReg $[14,15]$, an instrument that measures PA and energy 
expenditure (EE), and with the International Physical Activity Questionnaire [16].

The item assessing exercise frequency was included in all three SHoT studies, whereas the items assessing the intensity and duration of the exercise were only included in SHoT2018. As a measure of physical activity, the frequency variable was dichotomized using 2 times per week as the cut-off value (inactivity = "never", "less than once a week", "once a week").

Based on WHO's recommendation [4] that adults ( $\geq 18$ years) should get at least $30 \mathrm{~min}$ (or preferable 60 min for increased health benefits) of MVPA 5 days or more per week $(=150$ [or preferable 300 ] minutes per week) [4], two dichotomous recommendation variables were created based on the students' responses on all three exercise items: 1) MVPA: 150 mins/week: students answering both "Almost every day" on the frequency item, "I push myself so hard that I lose my breath and break into a sweat" on the intensity item, and " $30 \mathrm{mi}$ nutes or more" or "More than 1 hour" on the duration item. 2) MVPA: 300 mins/week: students answering both "Almost every day" on the frequency item, "I push myself so hard that I lose my breath and break into a sweat" on the intensity item, and "More than $1 \mathrm{~h}$ " on the duration item.

\section{Body mass index (BMI)}

BMI was calculated based on self-reported body weight $(\mathrm{kg})$ divided by squared height $\left(\mathrm{m}^{2}\right)[17,18]$. The BMI was then split into 4 categories: underweight $(\mathrm{BMI}<$ 18.5), normal weight (BMI 18.5-24.9), overweight (BMI 25.0-29.9) and obesity (BMI $\geq 30)[19]$.

\section{Statistical analyses}

We used IBM SPSS Statistics 25 for Windows (SPSS Inc., Chicago, IL) for all analyses. Independent samples t-tests and Pearson's chi-squared tests were used to examine differences in physical exercise and BMI in 2010, 2014 and 2018 among male and female students. Multinomial regression models were computed to obtain effect-size estimates of the association between physical exercise and BMI category. Results are presented as odds-ratios (ORs) with 95\% confidence intervals (95\% CIs), adjusted for gender and age. Missing values were handled using listwise deletion, and there was generally little missing data $(n<250$ of 50,054 on the three exercise items in SHoT 2018).

\section{Results}

\section{Physical exercise in SHoT2018}

Approximately two thirds (66\% in males and 68\% in females) reported exercising twice per week or more frequently, while one in four students (27\% in males and $22 \%$ in females) reported exercising almost every day. In contrast, 6 and $4 \%$ among the male and female students, respectively, reported that they never exercised. In terms of intensity of the exercise, the majority of both male (69\%) and females (73\%) students reported "pushing themselves so hard that they lose their breath and break into a sweat". More male than female students $(17 \%$ vs. $9 \%, p<.001)$ reported "pushing themselves to near exhaustion". A similar gender difference was also observed for exercise duration, with nearly half of the male students (48\%) reporting an average exercise duration of more than $1 \mathrm{~h}$, whereas less than one third (31\%) of the female students reporting this (see Fig. 1 for details).

In terms of meeting the minimum recommended criteria for both exercise frequency, intensity and duration (150 min per week of MVPA), $23.3 \%$ of male and $17.9 \%$ of female students, respectively, fulfilled these criteria (gender difference: $p<.001$ ). Employing the more recent and strict criteria of $300 \mathrm{~min}$ per week of MVPA, the corresponding proportions for male and female students were 16.8 and $9 \%$, respectively $(p<.001)$.

\section{Trend of physical exercise from 2010 to 2018}

There was an overall increase in students exercising twice or more per week from 2010 to 2014 (from 65.1 to $70.4 \%$ in males, and from 59.4 to $70.6 \%$ in females). However, this trend was no longer present, and to some extent reversed, in 2018, with 66.3 and $67.9 \%$ of the male and female students, respectively, reporting exercising twice or more per week in 2018. This trend was evident across all age groups (see Fig. 2 for details).

\section{Trend of BMI and obesity from 2010 to 2018}

There was small increase in BMI among male students from $2010 \quad(24.0 \quad(\mathrm{SD}=3.4)$ to $2014 \quad(24.2 \quad(\mathrm{SD}=3.5$, $\mathrm{t}(5019)=2.824, P=.002)$, and the BMI had increased significantly further in 2018 to $24.5(\mathrm{SD}=3.9, \mathrm{t}(10,201.5)=$ 5.078, $P<.001)$. The same pattern was observed in female students: from $22.7(\mathrm{SD}=2.7)$ in 2010 to $23.0(\mathrm{SD}=3.9)$ in $2014(\mathrm{t}[9021)=3.338, P<.001)$, and with a substantial increase from 2014 to 2018 (24.0, SD $=4.5, P<.001, \mathrm{t}(12$, $020.5)=19.542, P<.001)$. The increase was evident across all age groups, and as detailed in Fig. 3, the BMI was substantially higher among older students. Of note, there were no significant changes in body height in neither male students (182.2 cm [2010]; $181.9 \mathrm{~cm}$ [2014] and $182.2 \mathrm{~cm}$ [2018]) nor females students $(168.0 \mathrm{~cm} \mathrm{[2010],} 167.8 \mathrm{~cm}$ [2014] and $167.9 \mathrm{~cm} \mathrm{[2018]).}$

In terms of overweight/obesity, a similar pattern was observed for both men and women. While the prevalence of overweight/obesity in male students was $29 \%$ in 2010, the proportion of male students with a BMI over 25 had increased to $31.6 \%$ in 2014 and $36.4 \%$ in $2018(P<.001)$. The increase from 2014 to 2018 was even more pronounced in female students. Whereas $19.2 \%$ of the female students 


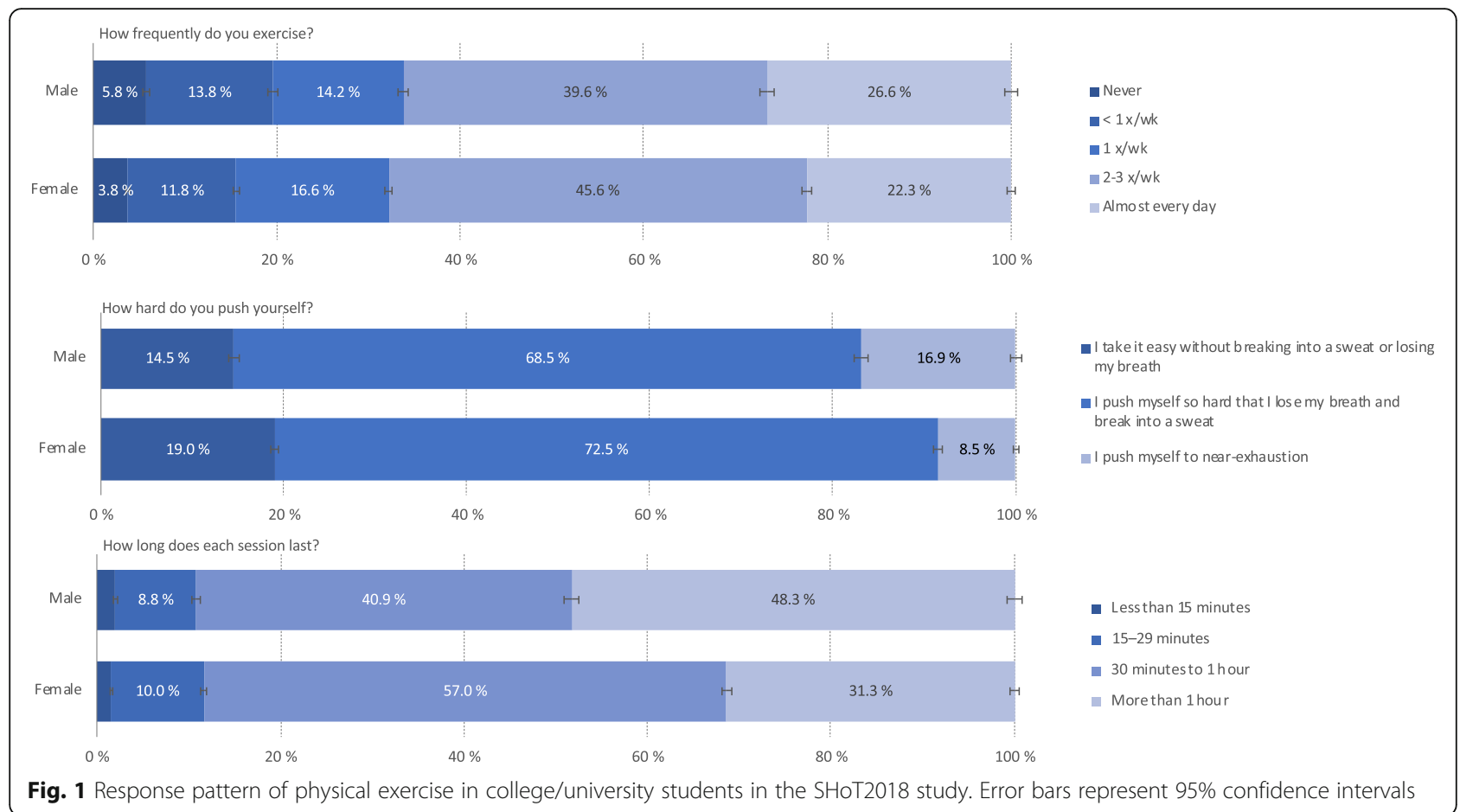

could be classified as overweight/obese, the prevalence had increased to $20.9 \%$ in 2014 and $30.5 \%$ in $2018(P<.001)$. These trends were similar across all age groups (see Fig. 3 for details), although the prevalence of overweight/obesity was substantially higher in the older age groups. For example, in 201837.3 and $49.1 \%$ of the female and male students, respectively, aged 26-35 years, had a BMI over 25. As also can been seen in Fig. 3 the prevalence of obesity (BMI > 30; displayed in shaded bars), increased in a similar pattern over time, with the strongest increase from 2014 to 2018.

\section{Association between age, physical exercise and BMI}

Figure 4 shows the proportion of students meeting the different exercise recommendations against BMI, stratified by gender and age groups. A clear age trend was observed for both male and female students. While about one in four students met the frequency criteria (exercising almost every day) at age $18-20$ years, this was reduced to about $18 \%$ in students aged 29-35 years. An even stronger age gradient was observed when examining the proportion of students meeting both the frequency, intensity and duration criteria;

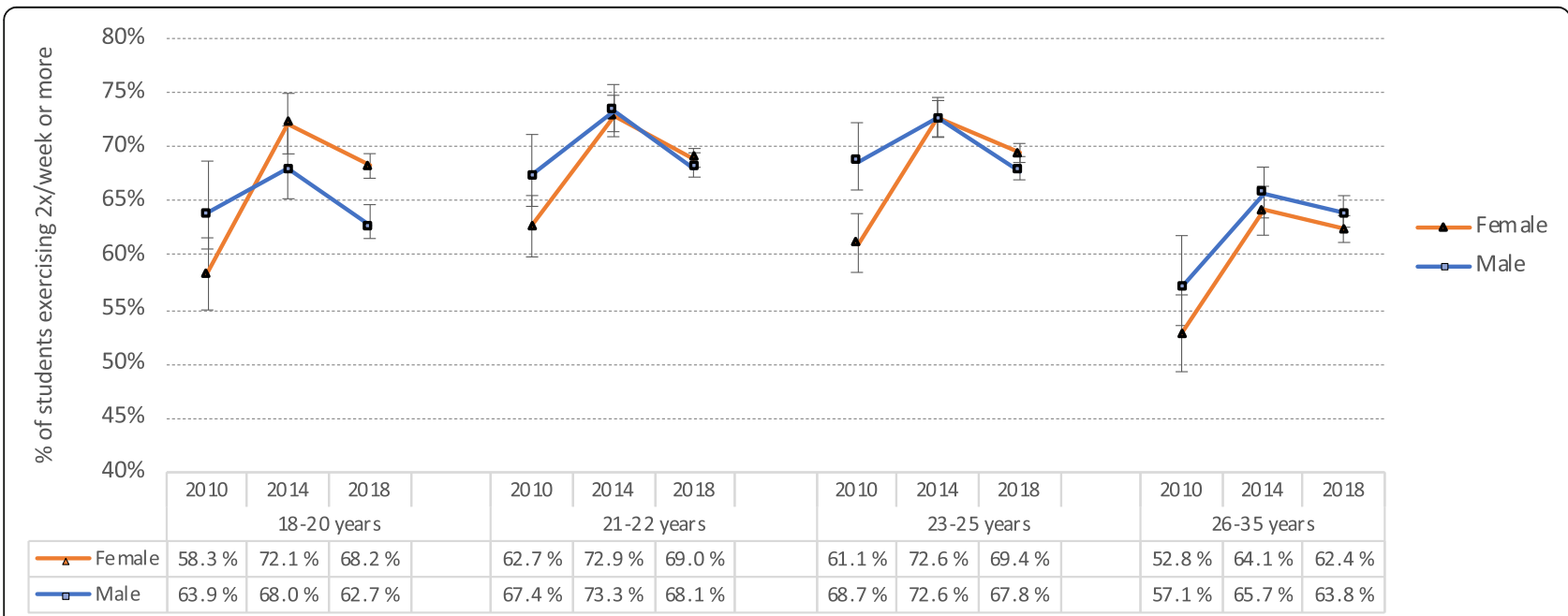

Fig. 2 Proportion of college/university students exercising twice or more weekly in 2010, 2014 and 2018 stratified by gender and age group. Error bars represent 95\% confidence intervals 


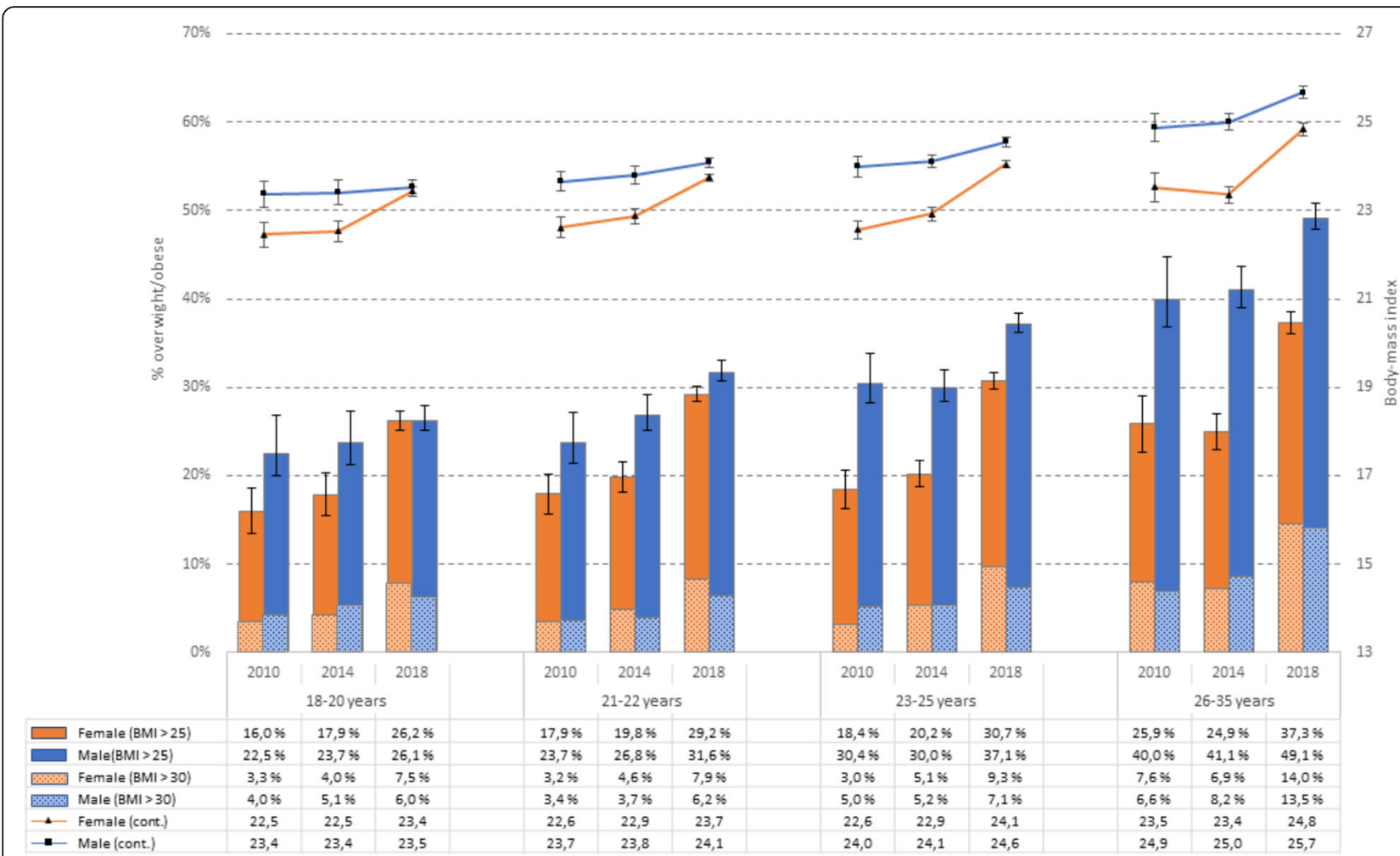

Fig. 3 Prevalence of overweight (BMI > 25; solid bars) and obesity (BMI > 30; shaded bars) on left axis, and continuous BMl on right axis among university and college students in 2010, 2014 and 2018 stratified by gender and age group. Error bars represent 95\% confidence intervals

in females, 20 and $11 \%$ of $18-20$-years-olds met all three criteria for 150 and 300 min per week of MVPA, respectively, while only 11 and $4 \%$, respectively, of the oldest age group did this. A similar decline was observed in males regarding the two exercise recommendations, from 23 and $18 \%$ in $18-20$-year-olds, to 14 and $8 \%$ in $29-35$-year-olds. This general decline in level of physical activity in older students was inversely associated with BMI, for which a significant increase with advancing age was observed (see Fig. 4 for details).

\section{Association between exercise frequency and BMI from 2010 to 2018}

Across all three time points, exercise frequency was associated with increased odds of being obese in a graded/dose-response manner; the less frequent his or
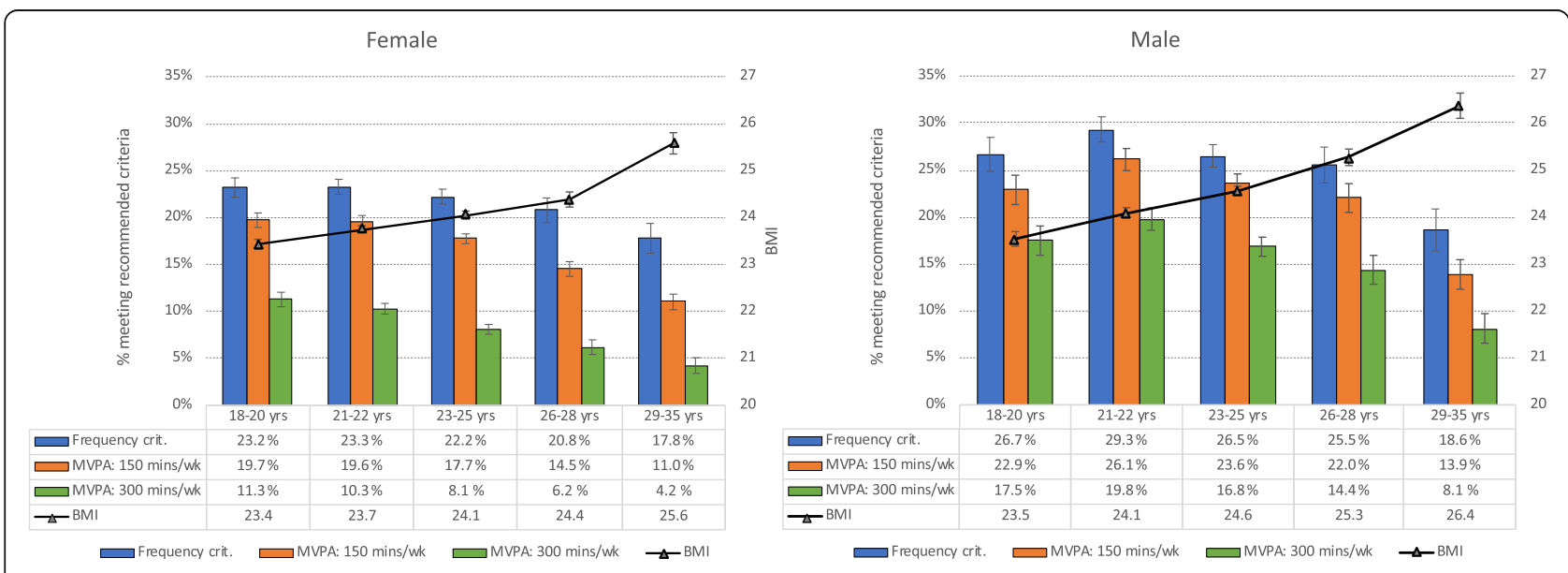

Fig. 4 Percentage of male and female students meeting different physical exercise recommendations (bars [left axis]) and BMI (black line on right axis), stratified by age groups 
she exercised, the higher the odds of having a BMI over 30. For example, in SHoT2018, exercising once per week was associated with an OR of 2.22 of being obese, whereas the OR increased to 3.29 in student never exercising, compared to exercising almost every day. Similar patterns were observed also in 2010 and 2014. In terms of odds of being overweight, a similar graded association was observed in 2010, but not in 2014 and 2018 (see Table 1 for details).

\section{Discussion}

This large national survey from 2018, inviting all fulltime Norwegian university and college students aged 18-35, has several notable findings. While two of three students in 2018 exercised twice or more per week, less than one of four male, and less than one of five female students, met the minimum recommended criteria for both exercise frequency, intensity and duration (150 min per week of MVPA). Overall, students exercised less in 2018 compared to 2014, but comparable to the levels in 2010. The prevalence of overweight increased substantially from 2010 to 2018, but especially in the last 4 years and among older female students. As expected, the associations between exercise and BMI were in a dose-response manner, and strong across all three waves.

\section{Comparisons to previous studies}

Inactivity is a well-recognized risk factor for developing or exacerbating a range of non-communicable diseases (NCS), and a range of studies worldwide have examined the prevalence of inactivity (i.e doing less than 150 min of MVPA per week). In a recent Lancet paper from 2018 including 1.9 million participants from 358 surveys and 168 countries, the authors reported a global age-standardised prevalence of insufficient physical activity of $27.5 \%$ (23.4\% in men and $31.7 \%$ in women), but with great regional differences [6]. Compared to these pooled analyses, the findings from the current 2018 study of students taking higher education in Norway, indicate that a substantially larger proportion fail to meet the recommended criteria of PA. However, we cannot disregard the possibility that some of these differences may be due to methodological issues, including slightly different operationalizations of both frequency, intensity and duration of physical exercise. As such, future studies are needed to verify both if and why the large majority of college and university students fail to meet the recommended criteria for physical activity.

In contrast to the many prevalence reports published on physical activity/inactivity, consistent data on trends of adult physical activity over time have been scarce, and to

Table 1 Odds-ratios of frequency of physical exercise (exposure reference category: Almost every day) associated with BMI category (outcome reference category: normal weight) among Norwegian university students in 2010, 2014 and 2018. ORs adjusted for age and gender

\begin{tabular}{|c|c|c|c|c|c|c|c|c|c|c|}
\hline \multirow[t]{2}{*}{ Exercise frequency } & \multicolumn{2}{|c|}{ Normal weight (reference) } & \multicolumn{4}{|c|}{ Overweight (BMI 25.0-29.9) } & \multicolumn{4}{|c|}{ Obesity (BMI $\geq 30)$} \\
\hline & $\%$ & (n) & $\%$ & (n) & OR & $95 \% \mathrm{Cl}$ & $\%$ & (n) & OR & $95 \% \mathrm{Cl}$ \\
\hline \multicolumn{11}{|l|}{2018} \\
\hline Never & $3.8 \%$ & $(1191)$ & $3.9 \%$ & $(442)$ & 1.12 & $0.99-1.26$ & $7.0 \%$ & (299) & $3.29^{* * *}$ & $2.82-3.84$ \\
\hline$<1 \times /$ wk & $11.0 \%$ & (3419) & $12.7 \%$ & (1440) & $1.28^{* * *}$ & $1.18-1.38$ & $18.8 \%$ & (805) & $3.00^{* * *}$ & $2.68-3.36$ \\
\hline $1 \times / w k$ & $15.1 \%$ & $(4684)$ & $16.3 \%$ & (1850) & $1.22^{* * *}$ & $1.14-1.31$ & $19.0 \%$ & (814) & $2.22^{* * *}$ & $1.98-2.48$ \\
\hline $2-3 \times / w k$ & $44.4 \%$ & (13797) & $44.3 \%$ & (5044) & $1.14^{* *}$ & $1.08-1.21$ & $40.9 \%$ & (1749) & $1.63^{* * *}$ & $1.48-1.79$ \\
\hline Almost every day (ref) & $25.7 \%$ & (7990) & $22.8 \%$ & (2599) & 1.00 & - & $14.2 \%$ & (606) & 1.00 & - \\
\hline \multicolumn{11}{|l|}{2014} \\
\hline Never & $11.4 \%$ & (1011) & $12.9 \%$ & (323) & 1.13 & $0.92-1.40$ & $20.2 \%$ & (136) & $2.79 * * *$ & $1.83-4.23$ \\
\hline$<1 \times /$ wk & $15.8 \%$ & (1395) & $17.9 \%$ & (447) & 1.18 & $0.96-1.44$ & $22.8 \%$ & (154) & $2.32 * * *$ & $1.54-3.51$ \\
\hline $1 \times / w k$ & $42.1 \%$ & (3726) & $39.0 \%$ & (975) & 0.99 & $0.82-1.18$ & $39.0 \%$ & (263) & $1.52^{*}$ & $1.02-2.26$ \\
\hline $2-3 \times / w k$ & $23.6 \%$ & (2090) & $23.0 \%$ & (576) & 1.02 & $0.84-1.23$ & $13.8 \%$ & (93) & 0.98 & $0.63-1.50$ \\
\hline Almost every day (ref) & $7.1 \%$ & (631) & $7.2 \%$ & (180) & 1.00 & - & $4.2 \%$ & (28) & 1.00 & - \\
\hline \multicolumn{11}{|l|}{2010} \\
\hline Never & $14.0 \%$ & (593) & $16.8 \%$ & (184) & $1.98^{* * *}$ & $1.33-2.94$ & $25.8 \%$ & (60) & $3.94^{* * *}$ & $1.60-9.71$ \\
\hline$<1 \times /$ wk & $20.9 \%$ & (887) & $23.1 \%$ & (253) & $1.86^{* * *}$ & $1.27-2.74$ & $29.2 \%$ & (68) & $3.03^{* * *}$ & $1.23-7.42$ \\
\hline $1 \times / w k$ & $42.1 \%$ & $(1785)$ & $41.6 \%$ & (456) & $1.65^{* *}$ & $1.14-2.40$ & $34.8 \%$ & (81) & 1.81 & $0.74-4.40$ \\
\hline $2-3 \times / w k$ & $17.9 \%$ & (757) & $15.2 \%$ & (166) & 1.34 & $0.90-1.99$ & $8.2 \%$ & (19) & 1.00 & $0.38-2.65$ \\
\hline Almost every day (ref) & $5.0 \%$ & (213) & $3.3 \%$ & (36) & 1.00 & - & $2.1 \%$ & (5) & 1.00 & - \\
\hline
\end{tabular}

*** $p<.001 ;{ }^{* *} p<.01 ;{ }^{*} p<.05 ;$ 
the best of our knowledge, no previous epidemiological trend studies have been conducted on college and university populations. Although the current study found a small increase in level of physical activity from 2010 to 2014, the overall proportion of inactivity remained relatively stable from 2010 to 2018, which is also in line with the conclusion from the Lancet report focusing on the general adults population [6].

Whereas the prevalence of inactivity have remained stable over the last decade, virtually all available data worldwide show that both the average BMI and proportion of overweight/obesity have increased over the last four decades, among children, adolescents, and especially adults [20]. Our findings are in line with these data, showing a stable increase in BMI and proportion of overweight/obesity in young adults from 2010 to 2018 . And while the increase was evident in both male and female students, we found that the prevalence of overweight and obesity had especially increased in older students, aged 26-35. These age and gender-specific findings are also similar to previous Norwegian trend data based in the large population-based HUNT study [21]. And while the HUNT study comprises participants aged 20-89 years of age, the authors of that study found that the largest increase of obesity from 1984 to 1986 to 2006-2008 was observed in the youngest age groups (20-40 years). The current study extends on these findings, and provides further evidence of no halt in the increase of obesity. If this trend continues at a similar pace, it will not be long until the majority of particularly older students (> 25 years) can be classified as overweight or obese.

\section{A global problem}

Despite the steadily escalation of observed weight gain over the last 4 decades, no country have successfully managed to stop or reverse this trend. As a simple explanation of weight gain, the concept of thermodynamics is are often used, with energy in minus energy out equal to weight profit or loss. Both these mechanisms seem to working negatively as countermeasures stop the weight gain. On one hand, the increased living standards and higher welfare is associated with more sedentary behaviour, a trend which also is also observed in low-income countries, characterized by urbanization, change in food culture and less more quiet-sitting.

\section{Public health implications}

The findings have notable public health implications, as they call attention to both the increasing prevalence of overweight and obesity over the last decade among students taking higher education. As the majority of these young adults failed to meet the recommended levels of frequency, duration and intensity of weekly exercise, our findings have obvious implications both from a public health perspective, but especially for the student welfare associations and educational institutions. Although these institutions and associations often encourage and facilitate their students to take part in a wide range of sports and exercise, our results indicate that they need to increase their efforts. For example, in terms of campus planning, more awareness is warranted regarding the need for good cycle paths and walkways. Another potential approach may be to adopt strategies from e.g. high schools, where physical exercise is a more integrated element in the typical school day, Although there is limited evidence of the effectiveness of broad awareness campaigns to increase the public's physical activity, there are studies suggesting that various forms of personalized media messages can be used to raise awareness, increase knowledge, and motivate a population to be more physically active.

In response to the alarming levels of inactivity, the World Health Organization (WHO) published in 2010 a set of recommendations to national policy makers on the total amount of physical activity needed to prevent noncommunicable diseases (NCDs), including overweight and obesity. Our findings suggest both that the large majority of young adults still fail to meet these recommendations, and that the recommendations are not sufficient to reduce the obesity epidemic. This dilemma shows that a broader approach is warranted, and the WHO recently launched a global action plan [22] on physical activity for 2018 to 2030 to make people more active. This action plan aims at providing a systembased framework of effective policy actions to countries in order to increase physical activity at all levels, emphasizing the need for a much broader response to achieve a paradigm shift in supporting all people being regularly active. This new WHO campaign will hopefully also be adopted regionally and locally by all educational institutions, and the next wave of the SHoT study (scheduled for 2022), will provide new insight in if the negative trend is possible to stop,

Another important finding in the current study is that female students were particularly at risk of being inactive and be classified as overweight. As such, increased efforts should be made to promote and create more tailored participation possibilities for female students. One option would be to focus more on raising the profile of women's sport in general, and to make the sporting environments to become more inclusive of women.

\section{Methodological considerations}

First, an important study limitation is the relatively low response rates for all three SHoT waves. But in contrast to similar cohort studies, especially of young adults, who have found lower response rates in recent years [23], the 
SHoT studies' response rates have actually increased from 2010 to 2018. Nevertheless, the response rate of the SHoT2018 was only $31 \%$, and as such, care should be taken when generalizing to the whole student population. One possible reason for the modest response rates may be the use of solely electronic survey platforms, which generally yield lower participation rates than for example paper-based surveys or face-to-face interviews [24]. Second, another limitation is that the three data collection methods were not completely identical. Although all three waves were web-based and included several of the same questionnaires, both the graphical user interface and months of data collection differed somewhat, which should be taken into account especially when examining trend results. A third study limitation is related to the physical activity measure, as it is more accurate to say that we assessed perceived intensity, as less fit individuals will feel exhausted by an intensity that a fit person will feel comfortable. Similarly, there may be other combinations of MVPA that can be performed to meet the recommended levels of physical activity. For example, 150 min of MVPA can be replaced with a lower duration of higher intensity, which are not accounted for in the current study. A fourth limitation is that while we did include a detailed assessment of energy expenditure, the SHoT study did not assess energy intake, which of course is vital when exploring the trend of obesity. Finally, there are limitations related to the use of BMI, as it measures excess weight rather than excess fat. BMI does not distinguish between excess fat, muscle, or bone mass, nor does it provide any indication of the distribution of fat among individuals. The strengths of the SHoT study include the very large sample size, in combination with several well-validated questionnaires.

\section{Conclusion}

The current study shows that that the large majority of young adults fail to meet international recommendations on exercise, and that the proportion of overweight is increasing in both genders and across all age groups. There is an urgent need for a broad approach to achieve a paradigm shift in supporting our college and university students to become more active, a responsibility that lies with both political and education institutions, as well as the student welfare associations.

\section{Abbreviations}

BMI: Body-mass index; MVPA: Moderate to vigorous physical activity; OR: Odds-ratio; PA: Physical activity; SHOT: Students' Halth and Wellbeing Study; WHO: World Health Organization

\section{Acknowledgements}

We wish to thank all students participating in the study, as well as the three largest student associations in Norway (SiO, Sammen, and SiT), who initiated and designed SHoT study.

\section{Authors' contributions}

Author MG and BS drafted the manuscript and conducted the statistical analyses. Authors BS and KJL were responsible for conception and design of the study, and KJL obtained funding. Authors HRE and KJL gave critical revision of the manuscript for important intellectual content. All authors have approved the manuscript being submitted.

\section{Funding}

SHOT 2018 has received funding from the Norwegian Ministry of Education and Research (2017) and the Norwegian Ministry of Health and Care Services (2016). The funding sources had no role in the design of the study and collection, analysis, and interpretation of data and in writing the manuscript.

\section{Availability of data and materials}

The SHoT dataset is administrated by the NIPH. Approval from a Norwegian regional committee for medical and health research ethics [https:// helseforskning.etikkom.no] is a pre-requirement. Guidelines for access to SHoT data are found at [https://www.fhi.no/en/more/access-to-data].

Ethics approval and consent to participate

The SHoT2018 study was approved by the Regional Committee for Medical and Health Research Ethics in Western Norway (no. 2017/1176). Informed consent was obtained electronically after the participants had received a detailed introduction to the study. Approvals for conducting the SHoT2010 and SHoT2014 studies were granted by the Data Protection Officer for research at the Norwegian Centre for Research Data.

\section{Consent for publication}

Not applicable.

\section{Competing interests}

The authors declare that they have no competing interests.

\section{Author details}

${ }^{1}$ Department of Sport, Food and Natural Sciences, Western Norway University of Applied Sciences, Bergen, Norway. ${ }^{2}$ Vestre Viken HF, Drammen, Norway. ${ }^{3}$ The Student Welfare Organisation of Oslo and Akershus (SiO), Oslo, Norway. ${ }^{4}$ Department of Health Promotion, Norwegian Institute of Public Health, Postboks 973 Sentrum, 5808 Bergen, Norway. ${ }^{5}$ Department of Research and Innovation, Helse Fonna HF, Haugesund, Norway. ${ }^{6}$ Department of Mental Health, Norwegian University of Science and Technology, Trondheim, Norway.

Received: 10 January 2019 Accepted: 20 September 2019

Published online: 23 October 2019

\section{References}

1. Finkelstein EA, Khavjou OA, Thompson H, Trogdon JG, Pan LP, Sherry B, et al. Obesity and severe obesity forecasts through 2030. Am J Prev Med. 2012;42(6):563-70

2. Luke A, Cooper RS. Physical activity does not influence obesity risk: time to clarify the public health message. Int J Epidemiol. 2013;42(6):1831-6.

3. Fisher G, Hunter GR, Allison DB. Commentary: physical activity does influence obesity risk when it actually occurs in sufficient amount. Int J Epidemiol. 2013;42(6):1845-8.

4. U.S. Centers for Disease Control and Prevention. Are there special recommendations for young people?. 2007. Available at: http://www.cdc. gov/nccdphp/dnpa/physical/recommendations/young.htm. 22 May 2007.

5. World Health Organiztion (WHO). Global action plan for the prevention and control of noncommunicable diseases 2013-2020. Geneva: World Health Organization; 2013.

6. Guthold R, Stevens GA, Riley LM, Bull FC. Worldwide trends in insufficient physical activity from 2001 to 2016: a pooled analysis of 358 population-based surveys with 1.9 million participants. Lancet Glob Health. 2018;6(10):E1077-E86.

7. Knuth $A G$, Hallel PC. Temporal trends in physical activity: a systematic review. J Phys Act Health. 2009;6(5):548-59.

8. Sivertsen B, Salo P, Mykletun A, Hysing M, Pallesen S, Krokstad S, et al. The bidirectional association between depression and insomnia: the HUNT study. Psychosom Med. 2012;74(7):758-65. 
9. Fountaine C, Liguori G, Mozumdar A, Schuna J. Physical activity and screen time sedentary behaviors in college students. International Journal of Exercise Science. 2011;4(2):102-12.

10. Peterson NE, Sirard JR, Kulbok PA, DeBoer MD, Erickson JM. Sedentary behavior and physical activity of young adult university students. Res Nurs Health. 2018:41(1):30-8.

11. Sivertsen B, Råkil H, Munkvik E, Lønning K. Cohort profile: the SHoT-study, a national health and wellbeing survey of Norwegian university students. BMJ Open. 2019;9:e025200. https://doi.org/10.1136/bmjopen-2018-025200.

12. Kurtze N, Rangul V, Hustvedt BE, Flanders WD. Reliability and validity of selfreported physical activity in the Nord-Trondelag health study (HUNT 2). Eur J Epidemiol. 2007;22(6):379-87.

13. Kurtze N, Rangul V, Hustvedt BE, Flanders WD. Reliability and validity of selfreported physical activity in the Nord-Trondelag health study: HUNT 1. Scand J Public Health. 2008;36(1):52-61.

14. Hustvedt BE, Svendsen M, Lovo A, Ellegard L, Hallen J, Tonstad S. Validation of ActiReg to measure physical activity and energy expenditure against doubly labelled water in obese persons. Br J Nutr. 2008;100(1):219-26.

15. Hustvedt BE, Christophersen A, Johnsen LR, Tomten H, McNeill G, Haggarty P et al. Description and validation of the ActiReg: a novel instrument to measure physical activity and energy expenditure. Br J Nutr. 2004;92(6):1001-8.

16. Craig $C L$, Marshall $A L$, Sjostrom M, Bauman AE, Booth ML, Ainsworth BE, et al. International physical activity questionnaire: 12-country reliability and validity. Med Sci Sports Exerc. 2003;35(8):1381-95.

17. Garrow JS, Webster J. Quetelet's index (W/H2) as a measure of fatness. Int J Obes. 1985;9(2):147-53.

18. Keys A, Fidanza F, Karvonen MJ, Kimura N, Taylor HL. Indices of relative weight and obesity. J Chronic Dis. 1972;25(6):329-43.

19. World Health Organization. Physical status: the use and interpretation of anthropometry. Report of a WHO Expert Committee. World Health Organ Tech Rep Ser. 1995;854:1-452.

20. N. C. D. Risk Factor Collaboration. Worldwide trends in body-mass index, underweight, overweight, and obesity from 1975 to 2016: a pooled analysis of 2416 population-based measurement studies in 128.9 million children, adolescents, and adults. Lancet. 2017:390(10113):2627-42.

21. Midthjell K, Lee CM, Langhammer A, Krokstad S, Holmen TL, Hveem K, et al. Trends in overweight and obesity over 22 years in a large adult population: the HUNT study, Norway. Clin Obes. 2013;3(1-2):12-20.

22. World Health Organiztion $(\mathrm{WHO})$. Global action plan on physical activity 2018-2030: more active people for a healthier world. Geneva: World Health Organization; 2018.

23. Krokstad S, Langhammer A, Hveem K, Holmen TL, Midthjell K, Stene TR, et al. Cohort profile: the HUNT study, Norway. Int J Epidemiol. 2013;42(4):968-77.

24. Dykema J, Stevenson J, Klein L, Kim Y, Day B. Effects of E-mailed versus mailed invitations and incentives on response rates, data quality, and costs in a web survey of university faculty. Soc Sci Comput Rev. 2013;31(3):359-70.

\section{Publisher's Note}

Springer Nature remains neutral with regard to jurisdictional claims in published maps and institutional affiliations.

\section{Ready to submit your research? Choose BMC and benefit from:}

- fast, convenient online submission

- thorough peer review by experienced researchers in your field

- rapid publication on acceptance

- support for research data, including large and complex data types

- gold Open Access which fosters wider collaboration and increased citations

- maximum visibility for your research: over $100 \mathrm{M}$ website views per year

At $\mathrm{BMC}$, research is always in progress.

Learn more biomedcentral.com/submissions 